\title{
Parametric Variations of Rectangular Microstrip Patch Antenna Designed for WLAN Application
}

\author{
Archana Tiwari ${ }^{1}$ and Dipika Sagne ${ }^{2}$ \\ ${ }^{1}$ Assistant Professor, Electronics Engineering Department, Shri \\ Ramdeobaba College of Engineering \& Management, Nagpur, India \\ ${ }^{2}$ Reserch Scholar, Indian Institute of Information Technology, Nagpur
}

\section{ABSTRACT}

Antennas are the key parameter for wireless communication and microstrip patch are the simplest form of planar antennas. Rectangular patch has attracted many applications like Wi-Fi, Wi-max, WLAN etc. The proposed work is concentrated on design, implementation and designing procedure of rectangular microstrip patch antenna with inset feed for Industrial-Scientific-and Medical (ISM) band applications. The paper shows the parametric variation to achieve good return loss at a targeted frequency. The best results in the variation were selected for fabrication. The paper shows the rectangular patch of dimension $28.3 \times 37.5 \mathrm{~mm}^{2}$ with a finite ground plane $39 \mathrm{x} 47.5 \mathrm{~mm}^{2}$. The patch is designed with the substrate FR4 with thickness $1.6 \mathrm{~mm}$, and antenna is fed with inset feeding technique with feed length 3.14 $\mathrm{mm}$. The paper presented with a considerable match between simulated and fabricated antenna results. The antenna is simulated using a CST tool and gain and return loss were obtained as $1.977 \mathrm{dBi}$ and $-19.25 \mathrm{~dB}$ respectively. The paper is targeted for Wireless Local Area Network (WLAN) application.

KEY WORDS: MICROSTRIP, PATCH, ANTENNA, INSET FEED, WLAN.

\section{INTRODUCTION}

Microstrip antennas are increasing their popularity in wireless communication due to low manufacturing cost, easy to integrate, good accuracy and light weight. In that Rectangular patch antenna are more popular because it is easy to design but it has disadvantage such as narrow impedance bandwidth (typically a few percent). Nowadays Industrial-Scientific-and Medical (ISM) band which is an unlicensed frequency band attracted different applications in wireless communication such as Wireless Local Area Network (WLAN: 2.4-2.484, 5.15-5.25, 5.25-

\section{ARTICLE INFORMATION}

*Corresponding Author: tiwariar@rknec.edu

Received 05th Oct 2020 Accepted after revision 25th Dec 2020

Print ISSN: 0974-6455 Online ISSN: 2321-4007 CODEN: BBRCBA

Thomson Reuters ISI Web of Science Clarivate Analytics USA and Crossref Indexed Journal

\section{Clarivate
Analytics}

NAAS Journal Score 2020 (4.31) SJIF: 2020 (7.728)

A Society of Science and Nature Publication,

Bhopal India 2020. All rights reserved.

Online Contents Available at: http//www.bbrc.in/

Doi: http://dx.doi.org/10.21786/bbrc/13.14/4
5.35, 5.47-5.725 and5.725-5.850 GHz) and Worldwide Interoperability for Microwave Access (WiMAX: 2.5-2.69, 3.40-3.69 and 5.25-5.85 GHz). One of the frequency bands of the ISM band is $2.40 \mathrm{GHz}-2.48 \mathrm{GHz}$ where the proposed antenna design is presented. The antenna can be fed with different feeding techniques like edge feed, aperture feed, coaxial feed etc.

P. K. Sarkar, I. Rahaman, M. N. Rahman, and Md. F. Hasan, discussed the investigation of compact antenna structure. Ramadan Ali, Al-Husseini Mohammed, Tawky Youssef, KabalanKarim Y., El-ajj Ali presented a frequency and Pattern-reconfigurable Microstrip Antenna for WLAN Applications is presented targeting the $2.4 \mathrm{GHz}$ frequency band. A Compact patch antenna for WLAN application were presented by Natarajamani S, S K Beheract S K Patra. A triangular microstrip patch antenna is proposed by Keon-Myung Lee, Young-Je Sung for multi-band applications, and designed using a chip capacitor and T-shaped slit. 
In the presented design the square patch is fed with the inset line-feed feeding technique, in which the microstrip feed line i.e. conducting strip is connected to the patch antenna, it is slightly inserted inside the microstrip patch. The dimension and the location of microstrip feed line is depends upon matching of impedance and dimensions of feed line is very narrow width as compared to patch antenna.

Figure 1. Rectangular patch antenna Design 5

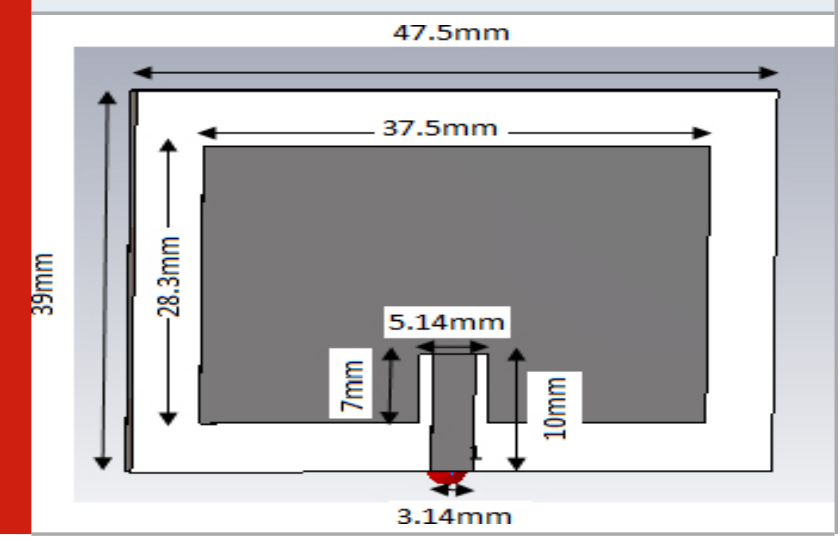

Table 1. Formulae And Calculation Of Rectangular Patch Antenna.

\begin{tabular}{|c|c|c|c|}
\hline Sr. No. & Antenna Parameters & Formula & Calculated values \\
\hline 1. & Width of the patch & $\mathrm{w}=\frac{c}{2 f r} \sqrt{\frac{2}{\epsilon r+1}}$ & $\mathrm{w}=37.26 \mathrm{~mm}$ \\
\hline 2. & $\begin{array}{l}\text { Effective dielectric } \\
\text { constant of an antenna }\end{array}$ & greff $=\frac{\varepsilon r+1}{2}+\frac{\varepsilon r-1}{2}\left[1+12 \frac{h}{w}\right]^{\frac{-1}{2}}$ & greff $=4.082 \mathrm{~mm}$ \\
\hline 3. & Length of the patch & $L=\frac{c}{2 f r \sqrt{\text { rreff }}}-2 \Delta L$ & $\iota=29.72 \mathrm{~mm}$ \\
\hline 4. & The effective length & $L e f f=L+2 \Delta L$ & Leff $=30.3 \mathrm{~mm}$ \\
\hline 5. & $\begin{array}{l}\text { The extended length } \\
\text { of an antenna }\end{array}$ & $\Delta l=h \cdot 0.412 \frac{(\text { rerff }+0.3)\left(\frac{W}{h}+0.264\right)}{(\text { rerf }-258)\left(\frac{W}{\frac{W}{2}-0.8}\right)}$ & $\Delta L=0.29 \mathrm{~mm}$ \\
\hline \multicolumn{4}{|c|}{$\begin{array}{l}\text { Where, c= velocity of light which is } 3 * 10^{8} \mathrm{~m} / \mathrm{s} \\
\varepsilon r=\text { dielectric constant of the substrate material }\end{array}$} \\
\hline
\end{tabular}

Design Consideration and its Flow: The rectangular patch design is considered with inset feed technique. The antenna design flow is as follows:

A. Selection of Frequency: The square patch antenna is designed to target ISM BAND frequency as its freely available band and there are many applications that work on it i.e. Wi-Fi, Wi-MAX, RF-ID etc. The proposed design is targeted to frequency $2.4 \mathrm{GHz}$ i.e 2.40 to $2.48 \mathrm{GHz}$ band.

\begin{tabular}{|c|c|c|c|c|c|}
\hline \multirow{2}{*}{$\begin{array}{l}\text { Parameter } \\
\text { (Unit in } \mathrm{mm} \text { ) }\end{array}$} & \multirow[b]{2}{*}{$\begin{array}{l}\text { Calculated } \\
\text { Parameters } \\
\text { (Design 1) }\end{array}$} & \multicolumn{4}{|c|}{ Parameter Variations } \\
\hline & & Design 2 & Design 3 & Design 4 & Design 5 \\
\hline Height of substrate (Hs) & 1.6 & 1.59 & 1.59 & 1.6 & 1.6 \\
\hline Width of substrate (Ws) & 60 & 58 & 56.9 & 40 & 45 \\
\hline Length of substrate (Ls) & 60 & 58 & 56.9 & 39 & 39 \\
\hline Length of Patch (Lp) & 29.72 & 28.45 & 37.26 & 28.45 & 28.3 \\
\hline Width of Patch (Wp) & 37.26 & 28.45 & 28.45 & 35 & 37.5 \\
\hline Width of Feed (Wf) & 3.03 & 3.03 & 3 & 3.14 & 3.14 \\
\hline \multirow[t]{2}{*}{ Length of Feed (Lf) } & 16.62 & 16.62 & 16.62 & 16.62 & 10 \\
\hline & \multicolumn{5}{|c|}{ Simulation Results } \\
\hline Impedance(ohm) & 30.56 & 37.02 & 39 & 40 & 49.02 \\
\hline Return loss (dB) & -21.23 & -21.98 & -6.27 & -11.53 & -19.25 \\
\hline Directivity (dB) & 6.557 & 6.307 & 6.536 & 6.269 & 5.897 \\
\hline Gain(dB) & -1.997 & 1.693 & 1.623 & 1.529 & 1.977 \\
\hline
\end{tabular}

B. Selection of Substrate Material: The most economic substrate used for designing purpose is FR-4 epoxy. Hence in the proposed design FR4 (lossy) dielectric is selected, with dielectric constant $\left(\varepsilon_{\mathrm{r}}\right)=4.4$, loss tangent $(\tan \delta)=0.01$ and substrate thickness of $(h)=1.6 \mathrm{~mm}$.

\section{Calculation of Dimensions of Rectangular Patch} Antenna: For $2.4 \mathrm{GHz}$ frequency, the patch antenna parameters like width and length can be calculated using theoretical considerations. The formulas are as follows in table 1.
D. Parametric Variation: While considering above parameters of antenna for designing, the results obtained in terms of resonant frequency, return loss and impedance matching were not satisfactory. Hence to improve results, different parameters of micro-strip patch antenna were modified. In order to match the impedance, changes were made in the width of the feed-line. By decreasing the width of the feed-line, it was observed that the input impedance of the patch antenna is getting matched. Table 2 shows the various parametric variations of microstrip patch antenna and shown its effect on simulated results 
in terms of return loss and resonating frequency and figure 1 shows the antenna design 5 .

E. Simulation Software: There was many software available like IE3D, CST, HFSS, ADS and CADFEKO etc. For proposed design the simulation results were presented using CST tool. CST is a tool which is specialized for the 3D Electromagnetic high frequency simulation. CST performance in terms of speed and accuracy makes this software more popular amongst technology leading RED departments. CST are used to analyze the behavior of high frequency devices such as antennas, filters, couplers etc. CST gives users a great flexibility in tackling a wide application range through the variety of available solver technologies. CST uses time Domain solver and the Frequency Domain solver models and it also facilitate to extract spice parameters.

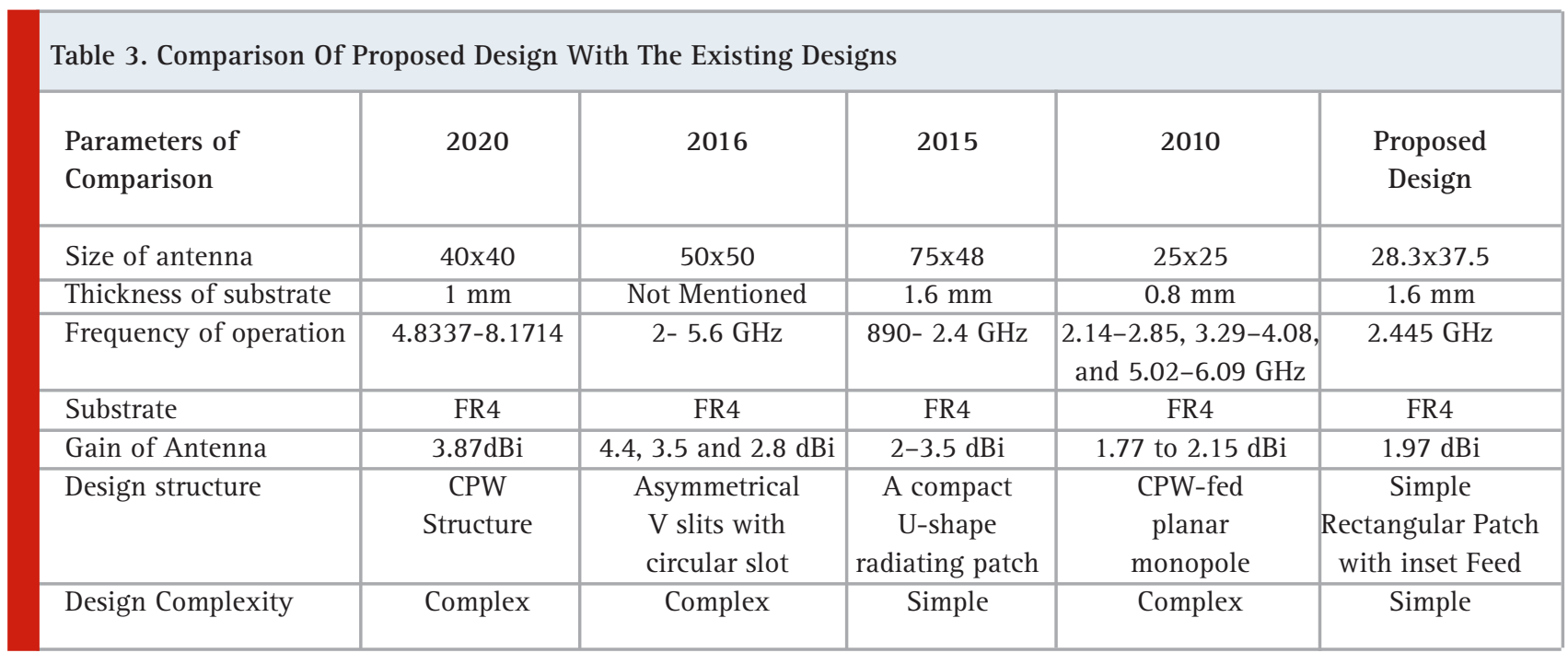

Figure 2: Simulated Return loss (S11 parameter) Plot for Design 5

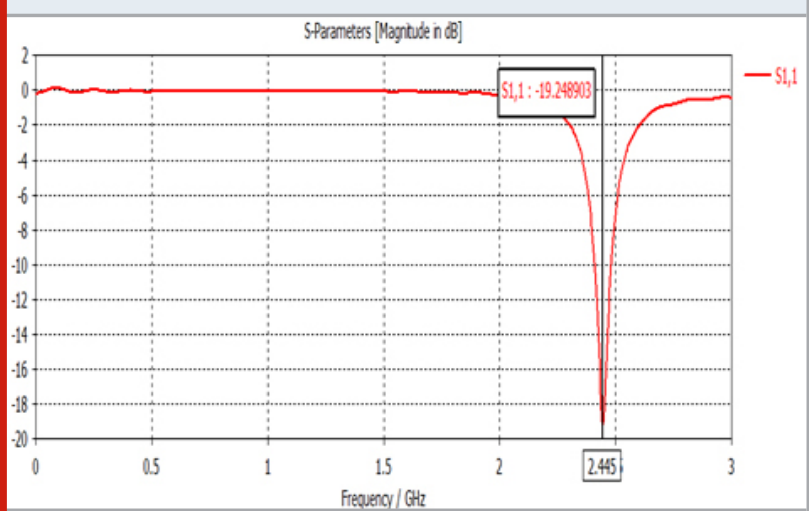

Figure 3: Simulated Impedance plot of design 5 on Smith chart

S-Parameters [Impedance View]

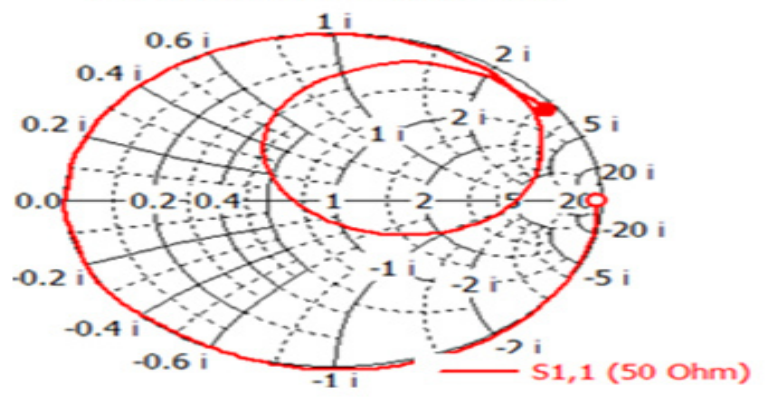

Figure 4: Simulated Radiation pattern of Design 5

Farfield Directivity Abs (Phi $=90)$

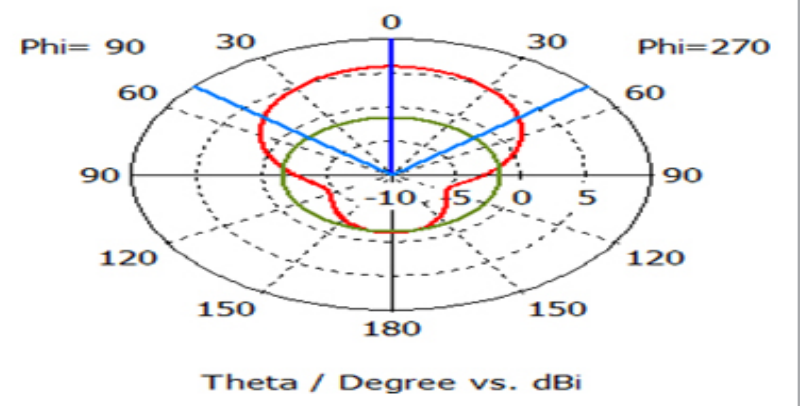

Figure 5 a, b: Top view and Bottom view of Fabricated Rectangular Patch

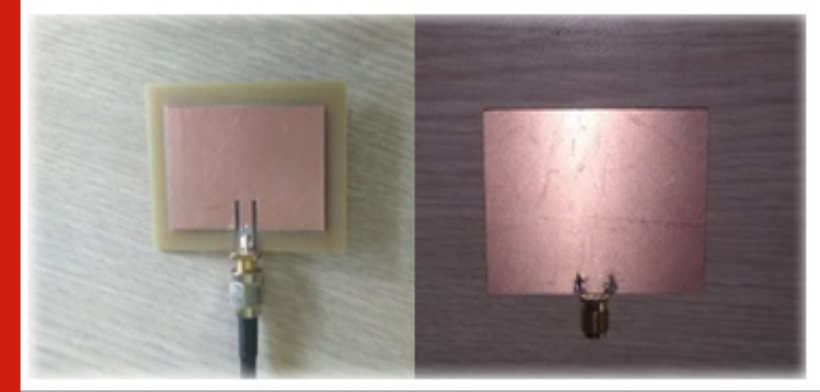

F. Simulation Results: After parametric variation of rectangular patch antenna, the best results were obtained in terms of return loss, impedance and resonating 
frequency is for design 5. Figure 2 shows bandwidth and return loss (S11 parameter) of rectangular patch antenna design 5 with central frequency 2.445 and figure 3 and 4 shows the impedance plot on smith chart and radiation pattern of design 5 respectively. The comparison with the existing designs is shown in table 3.

G. Fabricated Antenna Design: Rectangular patch antenna is fabricated on FR4 substrate, taking into consideration of dimensions of design 5. As the simulated results of design 5 were better results in terms of impedance, return loss and resonant frequency. Figure $5 \mathrm{a}$ and $5 \mathrm{~b}$ shows the top layer and bottom layer of fabricated rectangular patch antenna respectively. SMA connector is connected to the feed line having $50 \mathrm{Ohm}$ impedance to connect the measuring instrument like VNA for characterizing the antenna parameter of fabricated patch antenna.

Figure 6: Measurement setup of antenna with VNA

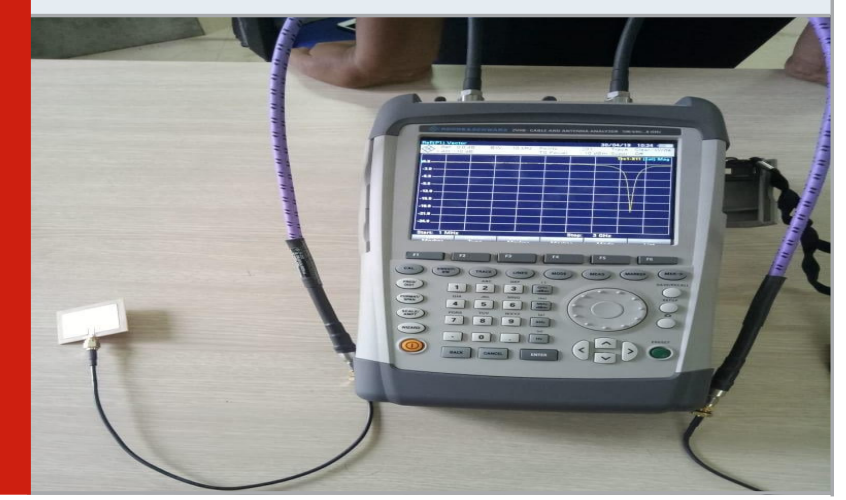

Figure 7: Frequency Vs return loss (S11 parameter) plot

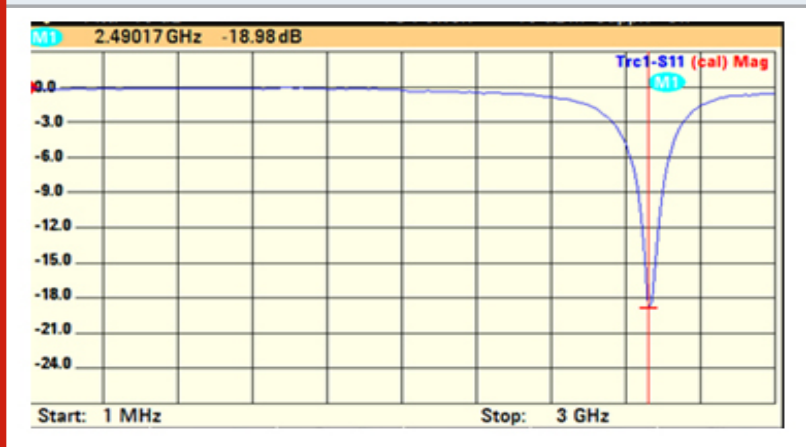

H. Characterization of Fabricated Antenna: The antenna parameters like return loss (S11 parameter), bandwidth and impedance plot of fabricated patch antenna was measured using Vector Network Analyser (VNA). VNA usually performs two types of measurements i.e. transmission and reflection. Transmission measurements pass the VNA stimulus signal through the device under test (DUT), which is then measured by the VNA receivers on the other side [7]. Figure 6 shows the measurement setup of antenna with VNA.

I. Fabrication Results: Figure 7 and 8 shows the frequency VS return loss (S11 parameter) plot and impedance plot

\section{Figure 8: Smith Chart of fabricated Antenna}

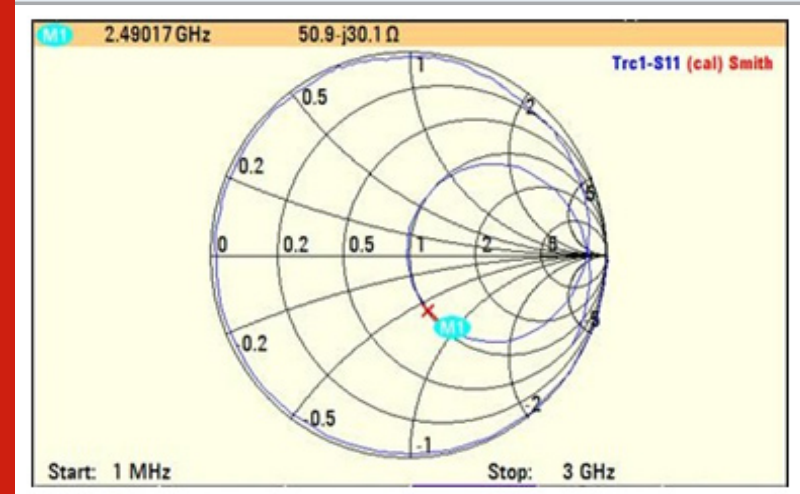

Table 3. Comparison Results Between Simulated And Fabricated Patch Antenna

\begin{tabular}{|l|c|c|}
\hline $\begin{array}{l}\text { Parameter } \\
\text { of } \\
\text { Comparison }\end{array}$ & $\begin{array}{c}\text { Simulated } \\
\text { Results of } \\
\text { Rectangular } \\
\text { Patch }\end{array}$ & $\begin{array}{c}\text { Fabricated } \\
\text { Results of } \\
\text { Rectangular Patch }\end{array}$ \\
\hline Resonant Frequency & $2.45 \mathrm{GHz}$ & $2.49 \mathrm{GHz}$ \\
\hline Measured Impedance & $\begin{array}{c}49.60 \mathrm{ohm} \\
50.9 \mathrm{ohm}\end{array}$ \\
\hline Return loss & $-19.25 \mathrm{~dB}$ & \\
& $-18.98 \mathrm{~dB}$ & \\
\hline
\end{tabular}

(smith chart) respectively of the fabricated antenna.

J. Comparison of the Simulated and Fabrication Results: It was observed that the fabricated results have shown considerable matching with the simulated results. Table 3 shows the comparison of both the Antennas i.e. simulated and fabricated rectangular Patch.

\section{CONCLUSION}

The design of rectangular patch of dimension $28.3 \times 37.5$ $\mathrm{mm} 2$ with ground plane $39 \mathrm{x} 47.5 \mathrm{~mm} 2$ was simulated and fabricated. The patch is designed and fabricated on FR4 substrate taking into consideration of thickness $1.6 \mathrm{~mm}$. The patch antenna is having $3.14 \mathrm{~mm}$ long inset feed. The patch antenna is simulated using a CST and then after parametric variations of patch the best simulation results obtained was for design 5 as resonant frequency $\sim 2.45 \mathrm{GHz}$, impedance as $49.6 \mathrm{ohm}$ and return loss of $-19.25 \mathrm{~dB}$. Hence design 5 was fabricated and characterized. The results after fabrication were found as resonant frequency $2.49 \mathrm{GHz}$, impedance as $50.9 \mathrm{ohm}$ and return loss of $-18.98 \mathrm{~dB}$. The proposed design for WLAN application has shown considerable match between simulated and implemented results. The disadvantages of this antenna are its low bandwidth, it can be improved by the technique insertion of slit and slot. Also, antenna gain can be also improved with the array formation. 


\section{REFERENCES}

Balanis C.A., "Antenna theory and design”, John Wiley and sons Inc. USA, 3rd edition.

Gurdeep Singh, Jaget Singh, (2012) Comparative Analysis of Microstrip Patch Antenna with Different Feeding Techniques", International Conference on Recent Advances and Future Trends in Information Technology Proceedings published in International Journal of Computer Applications (IJCA).

H. H. Tran, N. Nguyen-Trong, and H. C. Park, (2020) A Compact Dual Circularly Polarized Antenna with Wideband Operation and High Isolation," IEEE Access, vol. 8, pp. 182959-182965, doi: 10.1109/ ACCESS.2020.3022845.

H.-W. Liu, C.-H. Ku, and C.-F. Yang, (2010) Novel CPWFed Planar Monopole Antenna for WiMAX/WLAN Applications," Antennas Wirel. Propag. Lett., vol. 9, pp. 240-243.

Keon-Myung Lee, Young-Je Sung, Jung-Woo Baik, and Young-Sik Kim, (2008) A Triangular Microstrip Patch Antenna for Multi-band Applications”, 2008 Asia Pacific Microwave Conference, APMC.

Kumar G., Ray K.P., (2003) Broadband microstrip antennas", Artech house, Norwood, MA.

M. P. Jayakrishnan, K. Vasudevan, M. Ameen, P. Mohanan, and S. Mathew, (2016) Compact dual polarised V slit, stub and slot embedded circular patch antenna for UMTS/WiMAX/WLAN applications," Electronics Letters, vol. 52, no. 17, pp. 1425-1426.
Natarajamani S, S K Beheract S K Patra, (2010) A compact wide band patch antenna for WLAN aplications", Second International conference on Computing, Communication and Networking Technologies, pp: 1-4.

P. K. Sarkar, I. Rahaman, M. N. Rahman, and Md. F. Hasan, (2020) Investigation of Reduced Size Annular Ring Patch Antenna with EBG Structure for Wireless Applications," in 2020 11th International Conference on Computing, Communication and Networking Technologies (ICCCNT), Kharagpur, India, pp. 1-4.

Ramadan Ali, Al-Husseini Mohammed, Tawky Youssef, KabalanKarim Y., El-ajj Ali, (2010) A Novel Frequency/ Pattern-reconfigurable Microstrip Antenna for WLAN Applications", Proceedings of the Fourth European Conference on Antennas and Propagation (EuCAP), pp: 1-3.

V. K. Sambhe, R. N. Awale, and A. Wagh, (2015) Compact U-shape radiating patch with rectangular ground planar monopole antenna," The Journal of Engineering, vol. 2015, no. 2, pp. 54-58.

Viet Hoang, Tuan Tu Le, Qiu Yu Li and Hyun Chang Park, (2015) Quad-band circularly polarized antenna for 2.4/5.3/5.8 GHz WLAN and 3.5 GHz WiMAX applications", IEEE Antennas and Wireless Propagation Letters, volume 15.

Z. Ding, D. Zhang, and C. Ma, (2020) Broadband Antenna Design with Integrated CB-CPW and Parasitic Patch Structure for WLAN, RFID, Wimax, and 5G Applications," IEEE Access, vol. 8, pp. 42877-42883. 